\title{
MEDIDAS EDUCACIONAIS REFERENTES AO ENSINO FUNDAMENTAL DESENVOLVIDAS NO BRASIL NO PERÍODO DE 1996 À 2010
}

\author{
MEDIDAS EDUCACIONALES CONCERNIENTES A LA ESCUELA \\ PRIMARIA DESARROLLADAS EN BRASIL EN EL PERÍODO DE 1996 HASTA \\ 2010
}
EDUCATIONAL MEASURES RELATED TO ELEMENTARY EDUCATION DEVELOPED IN BRAZIL FROM 1996 TO 2010

Rosangela Maria BOENO ${ }^{1}$

Maria Elisabeth Blanck MIGUEL ${ }^{2}$

RESUMO: Este artigo apresenta os resultados de estudo documental e bibliográfico sobre as principais mudanças educacionais ocorridas no Brasil, durante os governos de Fernando Henrique Cardoso e Luiz Inácio Lula da Silva. O referido estudo centrou-se na análise dessas medidas, as quais atendem às exigências dos organismos internacionais. Para a melhor compreensão destas, utilizou-se de referências teóricas, legislação e documentos oficiais. Os resultados apontam que, embora as medidas aplicadas correspondam às solicitações da preparação do aluno para atender às exigências econômicas, também contribuem para a melhor aprendizagem dos alunos.

PALAVRAS-CHAVE: Política Educacional. Organismos Internacionais. Educação.

RESUMEN: Este artículo presenta los resultados del estudio documental y bibliográfico sobre los principales cambios educativos ocurridos en Brasil, durante los gobiernos de Fernando Henrique Cardoso y Luiz Inacio Lula da Silva. El referido estudio se centró en el análisis de estas medidas, las cuales atienden los requisitos de las organizaciones internacionales. Para mejor comprenderlas, fue utilizado referencias teóricas, la legislación y documentos oficiales. Los resultados indican que, aunque las medidas adoptadas corresponden a las solicitudes de preparación del estudiante para cumplir los requisitos económicos, también contribuyen para un mejor aprendizaje de los estudiantes.

PALABRAS CLAVE: Política Educacional. Las Organizaciones Internacionales. Educación.

ABSTRACT:This paper presents results of bibliographical and documentary study of the main educational changes in Brazil during the governments of Fernando Henrique

${ }^{1}$ Doutoranda em Educação pela Pontifícia Universidade Católica do Paraná. Professora do Magistério Superior da Universidade Tecnológica Federal do Paraná - Câmpus Dois Vizinhos. E-mail: rosangelaboeno@utfpr.edu.br.

${ }^{2}$ Doutora em História e Filosofia da Educação pela Pontifícia Universidade Católica de São Paulo. Professora Titular da Pontifícia Universidade Católica do Paraná. E-mail: maria.elisabeth@pucpr.br. 
Cardoso and Luiz Inacio Lula da Silva. The study focused on the analysis of some educational measures, which meet the requirements of international organizations. It had Isabel Maria Sabino de Farias, Sofia Lerche Vieira (2007), Livia Tommasi (1996), Dermeval Saviani (2008), and Carlos Alberto Jamil Cury (2010) as the main references, in addition to legislation and official documents. The results show that, although the measures applied correspond to the requests of the student's preparation to meet the economic requirements, they also contribute to the better learning of the students.

KEYWORDS: Educational Politics. International Organizations. Education.

\section{Introdução}

O século XXI é conhecido mundialmente como o século do conhecimento. A ideia prevalente é de que este é o século da informação acelerada, das modernas tecnologias, da competição e da qualidade, conceitos fundamentais ao processo produtivo e que também afetam a educação, principalmente porque esta busca atender orientações internacionais.

No Brasil, entretanto, os índices apresentados por meio das avaliações dos alunos demonstram que essa qualidade esperada do ensino, está aquém do que pode ser considerado um ensino de qualidade. As avaliações realizadas com os alunos ao final dos anos iniciais e finais do Ensino Fundamental indicam que os educandos apresentam dificuldades nas questões básicas referentes à leitura, interpretação e cálculo. Diante disso, são várias as alternativas utilizadas pelo governo visando atender às exigências dos organismos internacionais. Para isso, adota as medidas propostas por tais órgãos. Como exemplo, é possível citar: o Sistema de Avaliação da Educação Básica, o Plano de Desenvolvimento da Educação, o Índice de Desenvolvimento da Educação Básica (IDEB), dentre outros.

Observa-se que, com base em um discurso de melhoria da qualidade de ensino, são propostas reformas educacionais e promulgadas novas leis, as quais interferem, direta ou indiretamente, na forma de organização do ensino nos estados e municípios.

O presente artigo trata da história recente da educação brasileira. Apresenta um estudo sobre algumas medidas relacionadas ao Ensino Fundamental, a partir de 1990 até 2010. 


\section{Principais Medidas Educacionais do Ensino Fundamental (Anos Iniciais) a partir da aprovação da LDB n 9.394/96}

Para situar historicamente o leitor sobre o tema, optou-se pelo estudo e análise das principais medidas educacionais introduzidas no Brasil, principalmente após a promulgação da Lei de Diretrizes e Bases da Educação Nacional (Lei no 9.394/96), que atendem às exigências dos organismos internacionais. Partiu-se, assim, da análise do processo de avaliação da Educação Básica, incluindo o Sistema de Avaliação da Educação Básica (SAEB) a Prova Brasil, o Índice de Desenvolvimento da Educação Básica (IDEB) e sua relação com o Plano de Desenvolvimento da Educação (PDE).

O período que concerne à promulgação da LDB no 9.394/96, bem como o período posterior à sua aprovação, é marcado por sucessivas mudanças educacionais, principalmente no que diz respeito ao Ensino Fundamental. Nessa fase, o Brasil esteve sob o comando de dois presidentes, ambos eleitos para dois mandatos: Fernando Henrique Cardoso (01/01/1995 - 31/12/1998) e (01/01/1999 - 31/12/2003) e Luiz Inácio Lula da Silva (01/01/2004 - 31/12/2007 e 01/01/2008 - 31/12/2011).

No que diz respeito à educação, segundo Farias e Vieira (2007, p. 166), o governo Fernando Henrique Cardoso foi, aos poucos, tornando claro seu projeto para esta área, mas somente em 1996 houve uma efetiva "explicitação de rumos" da política educacional, uma vez que havia, nesse governo, um amplo conjunto de medidas que iam sendo deflagradas, tanto no âmbito do Executivo, quanto do Legislativo, referendando o projeto governamental.

As autoras descrevem:

Em primeiro lugar o governo faz aprovar no Congresso a Emenda Constitucional $\mathrm{n}^{\circ}$ 14, de 12 de setembro de 1996, modificando artigos do capítulo da educação da Constituição Federal e dando nova redação ao Art. 60 do Ato das Disposições Constitucionais Transitórias (ADCT). As alterações visam: permitir a intervenção da União nos Estados, caso estes não apliquem o valor mínimo exigido por lei (Art. 34); rever o dever do Estado na oferta de ensino fundamental para os que a ele não tiveram acesso em idade própria e de ensino médio (Art. 208); definir as responsabilidades das diversas esferas do Poder Público, em relação à oferta de ensino (Art. 211); detalhar os recursos aplicados pela União na erradicação do analfabetismo e na manutenção do ensino fundamental (Art. 212); e, prever a criação de fundo de natureza contábil para a manutenção e desenvolvimento do ensino fundamental e valorização de seu magistério (ADCT, Art. 60) (FARIAS; VIEIRA, 2007, p. 166). 
Nesse período, foi aprovada a Lei $\mathrm{n}^{\circ}$ 9.394, de 20 de dezembro de 1996, estabelecendo as Diretrizes e Bases da Educação Nacional (LDB). Destaca-se ainda o Sistema Nacional de Avaliação da Educação Básica (SAEB), criado em 1990, num período anterior à promulgação da Nova LDB, mas que passa por reformulações, destacando-se como principal a que ocorreu em 2005, por meio da Portaria $n^{\circ}$ 931, de 21 de março de 2005, implementando a Avaliação Nacional de Educação Básica $\left(\mathrm{ANEB}^{3}\right)$ e a Avaliação Nacional do Rendimento Escolar (ANRESC $\left.{ }^{4}\right)$. Sua repercussão é visível principalmente no início do século XXI.

Assim sendo, o controle do sistema escolar passou a ser exercido através de uma política de avaliação para todos os níveis. Outra medida adotada por Fernando Henrique Cardoso foi a retomada da elaboração do novo Plano Nacional de Educação já citado na LDB e aprovado pela Lei n ${ }^{\circ} 10.172$ em 09 de janeiro de 2001.

O Plano Nacional de Educação é uma Lei Federal que traça diretrizes e metas para a educação do País, com a duração de 10 anos e serve de apoio à elaboração dos planos estaduais e municipais de educação.

No que diz respeito aos governos de Luiz Inácio Lula da Silva, é possível destacar algumas de suas principais medidas para a Educação Básica, como a ampliação do Ensino Fundamental de Oito para Nove Anos, o Plano de Metas Compromisso Todos pela Educação, o Plano de Desenvolvimento da Educação (PDE), o Plano de Ações Articuladas (PAR) e o Índice de Desenvolvimento da Educação Básica (IDEB).

Apesar de várias medidas terem sido criadas visando melhorias no processo ensino-aprendizagem, há ainda uma lacuna significativa em termos de legislação no Brasil, pois não há um Sistema Nacional de Educação. Enquanto outros países já instituíram seus sistemas de ensino, esse assunto, no Brasil, continua em discussão.

Conforme Saviani (2010, p. 16):

${ }^{3}$ Avaliação Nacional da Educação Básica - Aneb: abrange, de maneira amostral, alunos das redes públicas e privadas do país, em áreas urbanas e rurais, matriculados na $4^{\mathrm{a}}$ série $/ 5^{\circ}$ ano e $8^{\mathrm{a}}$ série $/ 9^{\circ}$ ano do Ensino Fundamental e no $3^{\circ}$ ano do Ensino Médio, tendo como principal objetivo avaliar a qualidade, a equidade e a eficiência da educação brasileira. Apresenta os resultados do país como um todo, das regiões geográficas e das unidades da federação (BRASIL: INEP, 2011).

${ }^{4}$ Avaliação Nacional do Rendimento Escolar - Anresc (também denominada "Prova Brasil"): trata-se de uma avaliação censitária envolvendo os alunos da $4^{\mathrm{a}}$ série $/ 5^{\circ}$ ano e $8^{\mathrm{a}}$ série $/ 9^{\circ}$ ano do Ensino Fundamental das escolas públicas das redes municipais, estaduais e federal, com o objetivo de avaliar a qualidade do ensino ministrado nas escolas públicas. Participam desta avaliação as escolas que possuem, no mínimo, 20 alunos matriculados nas séries/anos avaliados, sendo os resultados disponibilizados por escola e por ente federativo (BRASIL: INEP, 2011). 
O Brasil foi retardando essa iniciativa e, com isso, foi acumulando um déficit histórico imenso no campo educacional, em contraste com os países que implantaram os respectivos sistemas nacionais de ensino tanto na Europa e América do Norte como na América Latina como ilustram os casos da Argentina, Chile e Uruguai. Estes equacionaram o problema na passagem do século XIX para o XX. O Brasil já ingressou no século XXI e continua postergando a dupla meta sempre proclamada de universalizar o ensino fundamental e erradicar o analfabetismo.

O Sistema Nacional de Educação foi um tema amplamente discutido nas conferências municipais e estaduais e na Conferência Nacional de Educação (CONAE, 2010). Sobre esta Conferência, Abicalil (2010, p. 03) afirma que a CONAE representa "um espaço privilegiado para que se possa avaliar e articular as definições da Lei de Diretrizes e Bases da Educação Nacional - LDB (7), do PNE e do próprio PDE, propondo-se alterações e mudanças nestes instrumentos de política pública” (grifo no original).

$\mathrm{Na}$ visão dos autores, mais precisamente os abordados nesta pesquisa, Dermeval Saviani, Carlos Roberto Jamil Cury e Carlos Augusto Abicalil, a instituição de um Sistema Nacional de Educação seria um avanço significativo para a Educação Brasileira.

Cury, em entrevista à CONAE, ao ser questionado sobre as alterações legais necessárias para a instituição de um Sistema Nacional de Educação no Brasil, respondeu que a implantação de um sistema só pode ser feito via emenda constitucional, sendo que outras medidas poderiam surgir via LDB. Ele salientou ainda que "a existência de um $\mathrm{CNE}^{5}$, de um $\mathrm{PNE}^{6}$, de um Fundeb ${ }^{7}$, de um sistema de avaliação apontam para a possibilidade de um sistema nacionalmente articulado com objetivos, metas e diretrizes devidamente efetivados” (CURY, 2010a, p. 03).

E, no artigo "Os desafios para a construção de um sistema nacional de educação", Cury afirma:

A organização de um sistema educacional é tanto a busca de organização pedagógica quanto uma via de jogo de poder. Por isso, cada vez que esse assunto foi pautado em Constituintes, Leis de Diretrizes e Bases, Planos Nacionais de Educação e Fundos de Financiamento, ele foi motivo de intensos debates, polêmicas,

${ }^{5}$ Conselho Nacional de Educação.

${ }^{6}$ Plano Nacional de Educação.

${ }^{7}$ Fundo de Manutenção e Desenvolvimento da Educação Básica e de Valorização dos Profissionais da Educação - FUNDEB (Lei n $11.494 / 07)$. 
sobretudo quando o adjetivo nacional entrou em pauta (CURY, 2010b, p. 19).

O referido autor argumenta que um dos motivos dessa polêmica é a insegurança das esferas de governo em relação à perda de sua autonomia.

Há o receio, por parte do segmento privado na educação escolar, de se ferir a liberdade de ensino e não falta quem assinale o perigo do monopólio estatal. E há também medo da parte da própria União quanto a uma presença mais efetiva, sobretudo ao que se refere ao financiamento da educação básica (CURY, 2010b, p. 19-20).

Nota-se que há a necessidade da implantação de um Sistema Nacional de Educação no Brasil. Essa é uma luta que vem se "arrastando" por anos. Acredita-se que a instituição de um sistema nacional de educação seria uma maneira de uniformizar as diretrizes para a educação de todo o país e consequentemente resultaria numa melhoria do processo ensino-aprendizagem. No entanto, as próprias esferas governamentais e também o setor privado sentem-se inseguros em relação à instituição de um Sistema Nacional de Educação. Tudo isso representa entraves significativos para a consolidação dessa importante conquista.

Apesar de não haver um sistema nacional de educação no Brasil, nas concepções de Saviani e Cury, expostas acima, o Brasil adota as medidas educacionais para avaliar a educação, principalmente as que provêm dos órgãos internacionais, principalmente as vinculadas à UNESCO e ao Banco Mundial. Tais medidas representam uma forma de controle do Ministério da Educação para monitorar os resultados da aprendizagem dos alunos.

\section{A Avaliação da Educação Básica e sua articulação com a proposta neoliberal}

Atrelada à ideia de competição, concorrência, qualidade está também a questão de aproximar cada vez mais a educação da questão mercadológica, tão em evidência nos últimos anos. No campo educacional essa tendência neoliberal se expressa de diversas formas, inclusive no que se refere às avaliações de desempenho.

Sobre isso, Gentili, ao fazer uma análise do neoliberalismo, discorre sobre a dupla lógica "aparentemente" contraditória das propostas neoliberais, ou seja, ele diz que ao mesmo tempo em que "transferem-se as instituições escolares da jurisdição federal para a provincial e, dessa, para a esfera municipal; propõe-se repassar os fundos 
públicos para níveis cada vez mais micro, evitando assim, a interferência 'perniciosa' do centralismo estatal [...]" (GENTILI, 1998, p. 24-25).

$\mathrm{O}$ autor assegura que, por outro lado e, ao mesmo tempo:

\begin{abstract}
Leva-se a cabo uma não menos poderosa estratégia centralizadora, fundada: a) no desenvolvimento de programas nacionais de avaliação dos sistemas educacionais altamente centralizados em seu planejamento e implementação (basicamente, provas de rendimento aplicadas à população estudantil); b) no planejamento hipercentralizado de reformas curriculares a partir das quais se chega a estabelecer os conteúdos básicos de um Currículo Nacional; e c) na implementação de programas nacionais de formação de professores que permitam a atualização dos docentes, segundo o plano curricular estabelecido na citada reforma (GENTILI, 1998, p. 24-25).
\end{abstract}

Verifica-se também que as provas de rendimento estão evidenciadas nas determinações do Banco Mundial, e seguem as Recomendações da UNESCO, porém buscam focar outros dados que não só os referentes ao número de matrículas ou frequência aos programas disponibilizados pelas instituições escolares.

A Declaração Mundial sobre Educação para Todos, proclamada pela UNESCO, em Jomtien na Tailândia, no período de 5 a 9 de março de 1990, constituiu o Plano de Ação para satisfazer as necessidades básicas de aprendizagem, reforçando a ideia de avaliação. Neste documento, observa-se que os termos: resultado, avaliação de rendimento ou de desempenho aparecem em diversas metas, conforme citações a seguir:

Artigo 4 - CONCENTRAR A ATENÇÃO NA APRENDIZAGEM: 1. [...] a educação básica deve estar centrada na aquisição e nos resultados efetivos da aprendizagem, e não mais exclusivamente na matrícula, frequência aos programas estabelecidos e preenchimento dos requisitos para a obtenção do diploma.[...]. Daí a necessidade de definir, nos programas educacionais, os níveis desejáveis de aquisição de conhecimentos e implementar sistemas de avaliação de desempenho. OBJETIVOS E METAS: 3. Melhoria dos resultados de aprendizagem, de modo que a percentagem convencionada de uma amostra de idade determinada (por exemplo, $80 \%$ da faixa etária de 14 anos), alcance ou ultrapasse o padrão desejável de aquisição de conhecimentos previamente definido [...] (UNICEF: DECLARAÇÃO MUNDIAL SOBRE EDUCAÇÃO ,1990, grifos das autoras).

Constata-se que o termo "desempenho" se faz presente em várias metas do Plano de Ação, atendendo, dessa forma, à política regulatória de controle que também foi sugerida pelo Banco Mundial. Verifica-se que o termo "avaliação" também aparece 
explicitamente no Plano de Desenvolvimento da Educação Básica (PDE), instituído em 2007 na $1^{a}$ gestão do governo Lula:

\begin{abstract}
A concretização do mandamento constitucional segundo o qual a União deve exercer 'em matéria educacional, função redistributiva e supletiva, de forma a garantir equalização de oportunidades educacionais e padrão mínimo de qualidade do ensino mediante assistência técnica e financeira aos estados, ao Distrito Federal e aos municípios' implicou revisão da postura da União, que a partir do PDE assumiu maiores compromissos - inclusive financeiros - e colocou à disposição dos estados, do Distrito Federal e dos municípios instrumentos eficazes de avaliação e de implementação de políticas de melhoria da qualidade da educação, sobretudo da educação básica pública (BRASIL, 2007a, p. 10).
\end{abstract}

Em resposta às determinações dessa política neoliberal e atendendo às propostas do Consenso de Washington (1989), da Declaração de Jomtien (1990) e das diretrizes do Plano de Metas Compromisso Todos pela Educação foi criada a proposta de avaliação do Sistema de Avaliação da Educação Básica (SAEB) com o objetivo de coletar informações sobre o desempenho acadêmico dos alunos brasileiros.

Sobre as avaliações do SAEB, o MEC no documento "SAEB - 2005, Primeiros resultados: Médias de desempenho do SAEB/2005 em perspectiva comparada" assegura:

Os dados, obtidos com a aplicação de provas aos alunos e de questionários a alunos, professores e diretores, permitem acompanhar a evolução do desempenho e dos diversos fatores associados à qualidade e à efetividade do ensino ministrado nas escolas (BRASIL/MEC: INEP, 2007d, p. 03).

Para compreender melhor a proposta de avaliação do governo federal brasileiro é fundamental a análise do Sistema de Avaliação da Educação Básica e da Prova Brasil.

\title{
SAEB (Sistema de Avaliação da Educação Básica) e Prova Brasil
}

O MEC, no documento "SAEB - 2005, PRIMEIROS RESULTADOS: Médias de desempenho do SAEB/2005 em perspectiva comparada, 2007" defende que a partir dessas informações, tanto o MEC quanto as Secretarias Estaduais e Municipais podem determinar ações voltadas para a correção das distorções e fragilidades identificadas, bem como conduzir seu apoio técnico e financeiro para a diminuição das desigualdades 
que ainda existem no sistema educacional brasileiro. Afirma ainda, que "realizar avaliações e divulgar resultados é uma forma do poder público prestar contas da sua atuação a alunos, professores, pais e à sociedade em geral, proporcionando uma visão clara do processo de ensino e das condições em que ele é desenvolvido" (BRASIL/MEC: INEP, 2007d, p. 03).

O MEC ressalta que o principal objetivo do SAEB é oferecer subsídios para a formulação e monitoramento de políticas públicas, contribuindo assim para a universalização do acesso e ampliação da qualidade, da equidade e da eficiência da educação brasileira. Ainda, o documento já referenciado apresenta um breve histórico sobre o SAEB:

\begin{abstract}
É sabido que o SAEB, desde sua primeira aplicação em nível nacional em 1990, tem procurado utilizar as melhores metodologias de coleta e análise de dados. Naquela ocasião, não havia sido introduzido no sistema um mecanismo que pudesse garantir a possibilidade de comparação de resultados de um ano para o outro. A cada ano os resultados eram analisados separadamente sendo, ao final, possível verificar a existência de aspectos comuns entre as avaliações, como por exemplo, conteúdos em que os alunos se saíam bem ou mal. Neste caso, realizava-se algo como uma meta análise dos resultados. A partir de 1995, porém, houve a intenção explícita de garantir a comparabilidade e assim, formar uma série histórica de resultados da avaliação [...]. Do ponto de vista dos instrumentos, os testes utilizados no SAEB têm por base as matrizes de referência, que orientam a construção e seleção de itens de avaliação. A cada processo de aperfeiçoamento pelo qual passam as matrizes, tabelas de conversão são criadas para que haja relação de comparabilidade entre os ciclos de avaliação (BRASIL/MEC: INEP, 2007d, p. 03-04).
\end{abstract}

No que diz respeito às amostras de alunos, o MEC destaca que em todas as edições do SAEB os procedimentos de amostragem basearam-se em metodologia científica, que garante precisão nas estimativas dos parâmetros populacionais; assegura que são amostras aleatórias, probabilísticas e representativas da população de referência. Destaca também, que a população de referência do SAEB eram os alunos que frequentavam a $4^{\mathrm{a}}$ e $8^{\mathrm{a}}$ séries do Ensino Fundamental, bem como os alunos da $3^{\mathrm{a}}$ série do Ensino Médio. A partir da aprovação da Lei n ${ }^{\circ}$ 11.274/06 que instituiu o Ensino Fundamental de Nove anos no Brasil, a população de referência passou a ser os alunos do $5^{\circ}$ e $9^{\circ}$ anos do Ensino Fundamental e como já mencionado, os alunos da $3^{\text {a }}$ série do Ensino Médio. 
Quanto à Prova Brasil, “os estudantes respondem a itens (questões) de Língua Portuguesa, com foco em leitura, e Matemática, com foco na resolução de problemas. No questionário socioeconômico, os estudantes fornecem informações sobre fatores de contexto que podem estar associados ao desempenho" (BRASIL: MEC, 2011). Além dos estudantes, os professores e os diretores das escolas avaliadas também respondem a um questionário, cujo objetivo é coletar informações sobre dados demográficos, perfil profissional e sobre as condições de trabalho no estabelecimento de ensino.

É importante destacar que "as médias de desempenho nessas avaliações também subsidiam o cálculo do Índice de Desenvolvimento da Educação Básica (Ideb), ao lado das taxas de aprovação nessas esferas" (BRASIL: MEC, 2011).

Para se chegar a uma compreensão mais ampla de todo esse processo de avaliação, faz-se necessário analisar o Índice de Desenvolvimento da Educação Básica e qual a sua relação com o Plano de Desenvolvimento da Educação Básica.

\section{IDEB (índice de Desenvolvimento da Educação Básica) e sua relação com o PDE (Plano de Desenvolvimento da Educação Básica)}

O PDE (Plano de Desenvolvimento da Educação) foi instituído em 2007, pelo Presidente da República, Luís Inácio Lula da Silva. O principal objetivo do Plano na concepção do MEC é melhorar substancialmente a educação oferecida às crianças, jovens e adultos (BRASIL: MEC, PDE, 2009, p. 04).

$\mathrm{Na}$ apresentação da publicação "PDE/PROVA BRASIL - Plano de Desenvolvimento da Educação, 2009”, o Ministério da Educação expõe: “O PDE sistematiza várias ações na busca de uma educação equitativa e de boa qualidade e se organiza em torno de quatro eixos: educação básica; educação superior; educação profissional e alfabetização" (BRASIL: MEC, PDE, 2009, p. 04).

Segundo o MEC, visando à mobilização da sociedade para concretizar o PDE, foi elaborado o Plano de Metas. Em relação à educação básica, as metas colaboram para que as escolas, bem como as secretarias de educação, proporcionem um atendimento de qualidade da aprendizagem aos alunos. O MEC enfatiza ainda, que o Plano de Metas Compromisso Todos pela Educação (Decreto $n^{\circ}$ 6.094, de 20 de abril de 2007) estabelece um conjunto de 28 diretrizes para que a União, os estados, o distrito federal e os municípios, unam esforços para superar a extrema desigualdade de oportunidades existentes no Brasil. 
Essas medidas convergiram para a criação de um instrumento, no caso, o IDEB, objetivando identificar as redes de ensino municipais e as escolas que apresentam maiores fragilidades no desempenho escolar, e que, por consequência, necessitam de uma maior atenção e apoio financeiro e de gestão.

O Ideb pretende ser o termômetro da qualidade da educação básica em todos os estados, municípios e escolas no Brasil, combinando dois indicadores: fluxo escolar (passagem dos alunos pelas séries sem repetir, avaliado pelo programa educacenso) e desempenho dos estudantes (avaliados pela Prova Brasil nas áreas de Língua Portuguesa e Matemática). [...] Assim, a avaliação passa a ser a primeira ação concreta para se aderir às metas do Compromisso e receber apoio técnico/financeiro do MEC, para que a educação brasileira dê um salto de qualidade (BRASIL: MEC, PDE, 2009, p. 04, grifo das autoras).

Com o objetivo de atender às necessidades educacionais dos estados e municípios, o MEC propôs um Plano de Ações Articuladas (PAR), priorizando as escolas com menor IDEB. Este convênio está vinculado à adesão ao Compromisso Todos pela Educação.

PAR (Plano de Ações Articuladas) é uma ferramenta de planejamento da política educacional brasileira comandada pelo Ministério da Educação (MEC). Assim que um município ou estado adere ao Compromisso Todos pela Educação - programa de 28 diretrizes para a melhoria do ensino nacional, o secretário responsável por essa área automaticamente se compromete a elaborar um diagnóstico e uma série de objetivos para a rede de ensino local. Essas metas devem ser alcançadas em até quatro anos e são estipuladas junto com diretores, coordenadores, professores e membros da comunidade. É a partir desses dados que o PDE (Plano de Desenvolvimento da Educação) pode fornecer apoio técnico e financeiro às administrações regionais (NAVARRO, 2009, s/p, grifo no original).

Em relação à priorização das escolas com menor IDEB, faz-se necessário uma conscientização a respeito dos investimentos que serão feitos nesses estabelecimentos de ensino, pois dentre outros, é fundamental o investimento em recursos humanos que atendam às exigências legais, ou seja, profissionais com formação e preferencialmente concursados, a fim de que possam dar prosseguimento ao trabalho desenvolvido nos anos posteriores.

Sobre o Ideb, Fernandes afirma ser uma iniciativa pioneira que reúne num mesmo indicador dois conceitos importantes para a qualidade da educação, que são os 
indicadores de fluxo (promoção, repetência e evasão) e as pontuações em exames padronizados obtidas por estudantes ao final de determinada etapa do sistema $\left(4^{\mathrm{a}}\right.$ e $8^{\mathrm{a}}$ séries do ensino fundamental e $3^{\circ}$ ano do ensino médio), os quais são usualmente utilizados para monitorar o sistema de ensino (FERNANDES, 2007).

O Ideb funciona como uma espécie de diagnóstico da educação básica, pois por meio desse índice é possível ter um indicativo do nível de conhecimento dos alunos em Língua Portuguesa e em Matemática, obtidos através do resultado do Saeb (Sistema de Avaliação da Educação Básica) e da Prova Brasil ${ }^{8}$.

Ele agrega ao enfoque pedagógico dos resultados das avaliações em larga escala do INEP, a possibilidade de resultados sintéticos, facilmente assimiláveis, que permitem traçar metas de qualidade educacional para os sistemas. O indicador é calculado a partir dos dados sobre aprovação escolar obtidos no censo escolar, e médias de desempenho nas avaliações do Inep, o Saeb - para as unidades da federação e para o país, e rova brasil - para os municípios (BRASIL, 2011, grifo no original).

O IDEB é medido a cada dois anos e o objetivo deste é que o país, a partir do alcance das suas metas, obtenhanota 6 (seis), nos Anos Iniciais do Ensino Fundamental em 2022, "média correspondente ao sistema educacional dos países desenvolvidos" (BRASIL, 2016). Sobre essa questão, Saviani analisa as medidas implementadas visando atingir melhoria na qualidade do ensino e denuncia a descontinuidade das políticas educacionais no Brasil que vão cada vez mais prorrogando os prazos para a consolidação dos principais objetivos, no caso, a erradicação do analfabetismo e a universalização do Ensino Fundamental:

O Brasil chegou ao final do século XX sem resolver um problema que os principais países resolveram na virada do século XIX para o XX: a universalização do ensino fundamental, com a consequente erradicação do analfabetismo. Para enfrentar esse problema a Constituição de 1988 previu, nas disposições transitórias, que o Poder Público nas suas três instâncias (a União, os estados e os municípios) deveria, pelos dez anos seguintes, destinar 50\% do orçamento educacional para essa dupla finalidade. Isso não foi feito. Quando esse prazo estava vencendo, o governo criou o FUNDEF com prazo de mais dez anos com essa finalidade; e a LDB, por sua vez, instituiu a década da educação; seguiu-se a aprovação em 2001, do Plano

${ }^{8}$ A Prova Brasil e o Sistema Nacional de Avaliação da Educação Básica (SAEB) são avaliações para diagnóstico, em larga escala, desenvolvidas pelo Instituto Nacional de Estudos e Pesquisas Educacionais Anísio Teixeira (Inep/MEC). Têm o objetivo de avaliar a qualidade do ensino oferecido pelo Sistema Nacional Brasileiro a partir de testes padronizados e questionários socioeconômicos (BRASIL. MEC, 2016). 
Nacional de Educação, que também se estenderia por dez anos. No final de 2006, ao se esgotarem os dez anos do prazo do FUNDEF, foi instituído o FUNDEB, com prazo de 14 anos, ou seja, até 2020. Em 2007, quando mais da metade do tempo do PNE já havia passado, veio um novo Plano, o Plano de Desenvolvimento da Educação (PDE) que estabeleceu um novo prazo, desta vez de quinze anos, projetando a solução do problema para 2022 (SAVIANI, 2010, p. 20-21).

O autor crescenta ainda: "Nesse diapasão, já podemos conjecturar sobre um novo Plano que será lançado em 2022 prevendo, quem sabe, mais 20 anos para resolver o mesmo problema (SAVIANI, 2010, p. 21). Diante disso, o Brasil fica atrás de muitos países que concentraram seus esforços e já conseguiram atingir as metas que o Brasil ainda busca.

Vale ressaltar que até 2007, as escolas que participavam da Prova Brasil, eram apenas as escolas urbanas e, em 2009 ocorreu um importante diferencial, ou seja, foram incluídas também as escolas rurais com mais de 20 alunos nas séries avaliadas (BRASIL, 2011). Isso representa uma importante conquista para a educação brasileira, pois a inclusão dos alunos das escolas rurais possibilita a ampliação do número de alunos avaliados, bem como, a oportunidade de comparação das notas obtidas pelos alunos que estudam nos diferentes espaços (urbanos e rurais).

Em face dessa realidade, a proposta de avaliação com base no Saeb considera resultados da aprendizagem aferidos por recursos quantitativos. Essa forma de regulação do ensino é recomendada por organismos internacionais como a Organização das Nações Unidas para a Educação, a Ciência e a Cultura - UNESCO e o Banco Mundial, principais estimuladores externos das reformas educacionais. O principal objetivo desses organismos é a liberação de financiamentos para os países, tendo como justificativa a "satisfação das necessidades básicas de aprendizagem" (COELHO, 2008, p. 235).

Neste sentido, Tommasi, em Seminário realizado em 28 e 29 de junho de 1995, na PUC-SP, já apresentava considerações sobre os projetos que o Banco Mundial estava financiando no Brasil e que, dentre outras medidas, apresentava as avaliações (TOMMASI, 1996).

Dessa maneira, observa-se que o objetivo dessas medidas é reduzir custos e introduzir na educação, as ideias e valores de mercado. 


\section{Considerações finais}

Neste artigo são analisadas as principais mudanças educacionais ocorridas no Brasil, durante os governos Fernando Henrique Cardoso e Luiz Inácio Lula da Silva, assim como as que foram implantadas a partir da aprovação da atual LDB (1996) até o ano de 2010, as quais atendem às exigências dos organismos internacionais: UNESCO e Banco Mundial. São elas, o Plano Nacional de Educação (Lei No 10.172/2001); a Avaliação da Educação Básica, incluindo o Sistema de Avaliação da Educação Básica (SAEB), a Prova Brasil, o Índice de Desenvolvimento da Educação Básica (IDEB) e sua relação com o Plano de Desenvolvimento da Educação Básica (PDE). Assim, muitas metas que o Brasil colocou em prática fazem parte do acordo estabelecido na Declaração Mundial sobre Educação para Todos realizado em Jomtien, na Tailândia, no período de 5 a 9 de março de 1990, quando foi constituído o Plano de Ação para satisfazer as necessidades básicas de aprendizagem (UNICEF - DECLARAÇÃO MUNDIAL DE EDUCAÇÃO PARA TODOS, 1990).

As Avaliações Nacionais, infelizmente, não conseguem demonstrar todo o conhecimento desenvolvido na escola; elas contemplam apenas um recorte do conhecimento, mas de certa forma, configuram-se em uma alternativa encontrada pelo MEC para analisar como está o ensino básico brasileiro, por meio de uma amostragem.

Essas medidas que atendem à política do Banco Mundial, oferecem importantes informações sobre a educação do País, pois a partir desse diagnóstico, o MEC, as secretarias de estado e as secretarias municipais de educação podem traçar estratégias de ação objetivando a melhoria da educação brasileira. No entanto, apesar das medidas implementadas, o Brasil ainda carece de um sistema nacional de educação que possa garantir a todos, a mesma educação.

\section{Referências}

ABICALIL, C. A. Construindo o sistema nacional articulado de educação. In BRASIL/ MEC: CONAE 2010. Disponível em: <http://conae.mec.gov.br〉. Acesso em: 20 jan. 2011.

BRASIL. Lei no 9.394, de 20 de dezembro de 1996. Estabelece as Diretrizes e Bases da Educação Nacional. Brasília, 1996. Disponível em: <http://www6.senado.gov.br/.../ListaTextoIntegral.action?id>. Acesso em: 01 jul. 2009. 
BRASIL. Lei no 10.172 de 9 de janeiro de 2001. Aprova o Plano Nacional de Educação e dá outras providências. Disponível em: <http://www.planalto.gov.br/ccivil/LEIS/L10172.htm>. Acesso em: 03 jul. 2009.

BRASIL. Portaria no 931, de 21 de março de 2005. Institui o Siatema de Avaliação da Educação Básic - SAEB, que será composto por dois processos de avaliação: a Avaliação Nacional da Educação Básica - ANEB, e a Avaliação Nacional do Rendimento Escolar - ANRESC. Brasília, 2005. Disponível em: <http://www.abmes.org.br/arquivos/legislacoes/Port_931_210305.pdf>. Acesso em: 10 jul. 2010.

BRASIL. Lei no 11. 274, de 6 de fevereiro de 2006. Altera a redação dos arts. 29, 30, 32 e 87 da Lei $n^{\circ}$ 9.394, de 20 de dezembro de 1996, que estabelece as diretrizes e bases da educação nacional, dispondo sobre a duração de 9 (nove) anos para o ensino fundamental, com matrícula obrigatória a partir dos 6 (seis) anos de idade. Disponível em: <http:// www.planalto.gov.br/ccivil/LEIS/>. Acesso em: 03 jul. 2009.

BRASIL. Ministério da Educação. O Plano de Desenvolvimento da Educação (PDE): razões, princípios e programas. Brasília, 2007a. Disponível em: <http://www.educarparacrescer.abril.com.br/.../par- 416141.html>. Acesso em: 26 jan. 2010.

BRASIL. Decreto no 6.094, de 20 de abril de 2007. Implementação do Plano de Metas Educação para todos. Brasília, 2007b. Disponível em: <http://www.planalto.gov.br/ccivil_03/_ato2007-2010/2007/decreto/d6094.htm>. Acesso em: 15 mar. 2016.

BRASIL. Lei no 11.494, de 20 de junho de 2007. Regulamenta o Fundo de Manutenção e Desenvolvimento da Educação Básica e de Valorização dos Profissionais da Educação - FUNDEB. Brasília, 2007c. Disponível em: <http://www.abrelivros.publier.com.br/abrelivros/texto.asp?id.>. Acesso em: 10 jul. 2009.

BRASIL. MEC. INEP. Primeiros resultados: médias de desempenho do SAEB/2005 em perspectiva comparada. Brasília, 2007d. Disponível em: <http://www.inep.gov.br/download/saeb/2005/SAEB1995_2005.pdf>. Acesso em: 23 jan. 2010.

BRASIL. MEC. PDE/ Prova Brasil: Plano de Desenvolvimento da Educação, Brasília, $2009 . \quad$ Disponível em: $<$ http://portal.mec.gov.br/index.php?option=com_docman\&view=download\&alias $=761$ 9-provabrasil-matriz pdf\&category_slug=fevereiro-2011-pdf\&Itemid=30192>. Acesso em: 25 jan. 2010.

BRASIL. INEP. Saeb. Brasília, 2011. Disponível em: <http://inep.gov.br/web/saeb/aneb-e-anresc >. Acesso em: 24 maio 2011.

BRASIL. INEP. Perguntas frequentes. Brasília, 2011. Disponível em: <http://provabrasil.inep.gov.br/perguntas-frequentes>. Acesso em: 29 out. 2011. 
BRASIL. MEC. Prova Brasil: histórico do SAEB. Brasília, 2011. Disponível em: <http://portal.inep.gov.br/web/saeb/historico>. Acesso em: 15 mar. 2016.

BRASIL. INEP. O que é o IDEB?. Brasília, 2011. Disponível em: <http://portal.inep.gov.br/web/portal-ideb/o-que-e-o-ideb>. Acesso em: 16 mar. 2016.

BRASIL. MEC. Ideb: Apresentação. Brasília, 2016. Disponível em: $<$ http://portal.mec.gov.br/index.php?option=com_content\&view=article\&id=180\&Itemi d=336>. Acesso em: 16 mar. 2016.

COELHO, M. I. M. C. Vinte anos de avaliação da educação básica no Brasil: aprendizagens e desafios. Ensaio: Avaliação e Políticas Públicas. Janeiro, v. 16, n.59, p. 229-258, abr./jun. 2008.

CURY, C. R. J. A Educação Escolar e o Sistema Nacional de Educação. In: BRASIL/ MEC. CONAE 2010. Brasília, 2010a. Disponível em <http://conae.mec.gov.br>. Acesso em: 20 jan. 2011.

CURY, C. R. J. Os desafios da Construção de um Sistema Nacional de Educação. In: BRASIL/ MEC. CONAE 2010. Brasília, 2010b. Disponível em: <http://conae.mec.gov.br>. Acesso em: 20 jan. 2011.

FARIAS, I. M. S. de; VIEIRA, S. L. Política Educacional no Brasil: introdução histórica. Brasília: Líber Livro Editora, 2007.

FERNANDES, R. Índice de Desenvolvimento da Educação Básica (IDEB). Brasília: Instituto Nacional de Estudos e Pesquisas Educacionais Anísio Teixeira, 2007. Disponível em: <http://www.odetemf.org.br/...ideb_indice_de_desenvolvimento_da_educação_basica.p df>. Acesso em: 11 maio 2009.

GENTILI, P. A falsificação do consenso: simulacro e imposição na reforma educacional do neoliberalismo. Petrópolis: Vozes, 1998.

NAVARRO, G. PDE: Por dentro do Plano de Ações Articuladas. Disponível em <http://www.educarparacrescer.abril.com.br/poitica.../par-416141.shtml>. Acesso em: 14 maio 2010.

SAVIANI, D. Sistema de Educação: Subsídio para a Conferência Nacional de Educação. In: BRASIL/ MEC. CONAE 2010. Disponível em: <http://conae.mec.gov.br>. Acesso em: 20 jan. 2011.

TOMMASI, L. de. Financiamento do Banco Mundial no setor educacional brasileiro: os projetos em fase de implantação. In: TOMMASI, L. et al (ORGS). O Banco Mundial e as políticas educacionais. São Paulo: Cortez Editora, 1996. Cap. V, p. 195-227.

UNICEF. Declaração Mundial sobre Educação para Todos. Tailândia, 1990. Disponível em: <https://www.unicef.org/brazil/pt/resources_10230.htm>. Acesso em: 18 jan. 2010. 


\section{Como referenciar este artigo}

BOENO; Rosangela Maria.; BLANCK MIGUEL; Maria Elisabeth. Medidas educacionais referentes ao ensino fundamental desenvolvidas no brasil no período de 1996 à 2010. Revista on line de Política e Gestão Educacional, Araraquara, v.21, n.1, p. 7-23, 2017. Disponível em: <http://dx.doi.org/10.22633/rpge.v21.n.1.2017.9604>. ISSN: 1519-9029.

Submetido em: 26/03/2017

Aprovado em: 30/03/2017 